\title{
La obsesión de Salvador Dalí por la ciencia
}

\author{
Salvador Dalís \\ obsession with science
}

Mònica López Ferrado

Periodista científica. Investigadora del Observatorio de la comunicación científica, Universidad Pompeu Fabra, Barcelona.

Travessera de Gracia, $1541^{\circ} 1 \mathrm{~A}$ 08012 Barcelona - España mlopez@mediapro.es
LOPEZ FERRADO, M.: La obsesión de Salvador Dalí por la ciencia. História, Ciências, Saúde - Manguinhos, v. 13 (suplemento), p. 125-31, octubre 2006.

El objetivo de este trabajo es hacer visible el interés de Salvador Dalí hacia la ciencia, a lo largo de su vida. Aunque ese interés haya quedado eclipsado por la figura excéntrica del artista, detrás del tópico se encuentra otro Dalí que intenta fusionar arte y ciencia. El pintor se alejó de los surrealistas en determinado periodo de su vida, pero nunca se distanció de la ciencia, sino que acompañó de muy cerca los descubrimientos científicos - la bomba atómica, la estructura del ADN - y siempre lo enseñó en su obra. El pintor mantuvo contacto y vínculos de amistad con algunos científicos, como Juan Oró, Jorge Wagensberg Matila Ghyka, Thomas Banchoff y René Thom; los Nobel Dennis Gabor, Severo Ochoa, Ilya Prigogine y James Watson. Dalí falleció acunado por cartas y libros de Stephen Hawking, Matila Ghyka y Erwin Schrödinger.

PALABRAS CLAVE: ciencia; arte; pintura; matemáticas; ADN; física; psicoanálisis; documental.

LOPEZ FERRADO, M.: Salvador Dalí's obsession with science.

História, Ciências, Saúde-Manguinhos, v. 13 (suplemento), p. 125-31, October 2006.

The article makes evident Salvador Dali's lifelong interest in science. Although the artist's eccentric figure overshadowed this interest, hidden behind the topic is another Dali who sought to merge art and science. Although the painter distanced himself from surrealists for a time, he never detached himself from science. To the contrary, he kept well abreast of scientific discoveries - the atom bomb, the structure of DNA - and always depicted these in his work. He was in contact and maintained friendships with scientists like Juan Oró, Jorge Wagensberg, Matila Ghyka, Thomas Banchoff, and René Thom, as well as Nobel prize winners Dennis Gabor, Severo Ochoa, Ilya Prigogine, and James Watson. Dali passed away surrounded by the letters and books of Stephen Hawking, Matila Ghyka, and Erwin Schrödinger.

KEYWORDS: science; art; painting; mathematics; DNA; physics; psychoanalysis; documentary. 
F in de año de 1965. James D. Watson, uno de los descubridores de la estructura del ADN, pasea por las calles de Nueva York. Cuando pasa por delante del hotel St. Regis no puede resistir entrar. En el hall, escribe una nota: "La segunda persona más brillante del mundo quiere conocer a la más brillante". Va dirigida a Salvador Dalí, que vive en el hotel la mitad del año. Mientras el recepcionista sube a la suite del artista, Watson recuerda un cuadro del pintor, "Galadesoxyrribonucleicacid", la primera tela dedicada al descubrimiento que le dio el premio Nobel. En menos de 10 minutos el mensaje de Watson ha hecho efecto y Dalí está ante él.

Este es tan sólo uno de los muchos episodios que muestran el interés de Dalí por la ciencia, que fue eclipsado por la figura excéntrica del artista. Detrás del tópico se encuentra otro Dalí que intenta fusionar arte y ciencia. Dos años de investigación para documentar cuándo y cómo Dalí se relacionó con el psicoanálisis, las matemáticas, la teoría de la relatividad, la física cuántica y la ciencia del ADN han dado como resultado el documental "Dimensión Dalí, , producido por Media 3.14 (Mediapro).

El documental recoge el testimonio de muchos de los científicos que lo conocieron, así como la documentación que muestra cómo incorporó la ciencia a su obra. En los archivos personales del pintor se encuentran más de cien títulos de disciplinas científicas diversas, algunos anotados y con comentarios en los márgenes, y parte de la correspondencia que mantuvo con algunos científicos. Entre sus amistades se encuentran los matemáticos Matila Ghyka, Thomas Banchoff y René Thom; los Nobel Dennis Gabor, Severo Ochoa, Ilya Prigogine y James Watson; los científicos españoles Juan Oró y Jorge Wagensberg, y muchos otros a quienes consultó puntualmente sobre temas que quería desarrollar en su obra.

La ciencia fue una constante en su vida y su rastro se encuentra incluso en su firma, que esconde una figura científica: la corona daliniana, que utilizó por primera vez en 1938, es la imagen estroboscópica de la gota de leche cayendo que el científico Harold Edgerton consiguió captar. Lo cierto es que dos obsesiones guiaron la vida de Dalí: su mujer Gala y la ciencia.

\section{Física y psicoanálisis}

“Todo pintor pinta la cosmogonía de sí mismo: Rafael pinta la cosmogonía del Renacimiento y Dalí pinta la era atómica y la era freudiana", afirma Dalí en una entrevista en los años 50.

La física y el psicoanálisis son, sin dudas, las dos ciencias que cambiaron la visión del mundo a principios del siglo XX. Desde su juventud, Dalí muestra interés por ambas. Su primer contacto con Freud y las teorías de la relatividad de Einstein se dio en los años 
20, cuando siendo un estudiante de pintura en Madrid, se alojó en la Residencia de Estudiantes, un lugar repleto de jóvenes intelectuales de la época, tanto del campo de las ciencias como de las letras. Encontramos una foto del joven Dalí, junto a García-Lorca, en la que aparece con una revista científica de la época, Science $\mathcal{E}$ Invention, bajo el brazo. Parece ser que en la Residencia le gustaba visitar, junto al poeta, los laboratorios de ciencias.

El interés más profundo por estas disciplinas llegó años más tarde, cuando se marchó a Francia y entró en el movimiento surrealista. No paró hasta que el escritor Stefan Zweig consiguió que Freud lo recibiese en 1938 en su casa de Londres. En el documental, el mismo Dalí explica el encuentro en el que acabó enfadado porque Freud no quiso leer su tesis sobre el método paranoicocrítico, en el que desarrolla un método de creación basado en los conocimientos que había adquirido sobre el funcionamiento de la mente. En una carta que el padre del psicoanálisis escribió a Zweig, describe a Dalí como un prototipo de español fanático.

Los surrealistas son quienes sumergieron a Dalí dentro del mundo de la física. La nueva realidad que proponía la nueva teoría de la relatividad, seguida por las teorías de la física cuántica, eran algo extraordinario para los surrealistas. "Dalí estaba fascinado por la teoría de la relatividad porque ofrecía al surrealismo la idea que la realidad no podía reducirse a un único flujo", explica Gavin Parkinson, historiador del arte de la Universidad de Oxford.

La nueva física cuántica proponía un mundo donde no existía el determinismo, donde las partículas podían encontrar-se en dos lugares al mismo tiempo, donde la identidad de los objetos se creaba con el mismo acto de observación. Eran conceptos difíciles de entender pero que abrían camino a la imaginación. Eran ideas tan estimulantes que se convirtieron en un tema recurrente en el laboratorio de creación surrealista y, por lo tanto, de sus publicaciones experimentales.

En los artículos que Dalí publicó en los años treinta, se encuentran muchas referencias al nuevo mundo que propone la física. Un ejemplo es su texto "La cabra sanitaria", donde dice que "la física debe formar la nueva geometría del pensamiento, y será precisamente el delirio de la interpretación paranoica".

\section{Mi padre ya no es Freud, sino Heisenberg}

En los años 40, llega la ruptura de Dalí y el movimiento surrealista. Dalí se traslada a Nueva York. En aquellos años, cae la bomba atómica, hecho que pone en evidencia las grandes implicaciones de los avances de la física nuclear. Este hecho abre un nuevo camino en la obra de Dalí. En sus cuadros empieza a pintar objetos en suspensión, que se descomponen en partículas 
que flotan en el espacio. Es la época que se denomina mística nuclear. "Mi padre ya no es Freud, es Heisenberg", afirma Dalí en su manifiesto místico. Empieza a devorar libros de estas disciplinas. Broglie, Heisenberg, Schrödinger son sus autores preferidos. Además se suscribe a la revista americana de divulgación científica Scientific American.

Dalí era una persona bien informada sobre ciencia, tal y como afirman los testimonios recogidos en el documental. Tanto sus libros como las revistas contienen anotaciones que se corresponden con elementos aparecidos en sus cuadros y en sus escritos. Un ejemplo es el libro La Geometría del arte y la vida del matemático rumano Matila Ghyka, con quien colaboró en uno de sus cuadros más conocidos: "Leda atómica".

A Dalí también le interesaba la aplicación de las matemáticas en el arte, a la manera de los grandes clásicos, y así lo hizo incorporando el número de oro a algunos de sus cuadros más memorables.

\section{La cuarta dimensión}

"Los pensadores y literatos no me aportan absolutamente nada. Los científicos, todo, incluso la inmortalidad del alma", afirma Dalí en otra de las entrevistas de archivo incluidas en el documental. Una de las almas científicas que conectó más con Dalí es Thomas Banchoff, matemático y profesor en la Brown University, en Providence (USA). El destino quiso que entrasen en contacto en 1975, cuando el Washington Post publicó un artículo sobre la tesis del joven Banchoff sobre la visualización tridimensional de objetos de dimensiones superiores. El artículo, ilustrado con una reproducción del "Corpus hipercubicus", que Dalí pintó en 1951, captó la atención del pintor. El joven científico recibió una llamada: “El señor Dalí quiere verle en el St. Regis". Banchoff se quedó petrificado y lo primero que le pasó por la cabeza es que Dalí quería ponerle algún tipo de denuncia por haber utilizado el cuadro para su tesis. Nada más lejos de la realidad. Dalí sentía simple curiosidad por conocer a aquel matemático que había sabido interpretar lo que quería decir con sus cuadros.

Con aquella primera conversación surge una amistad que duró muchos años. Banchoff explica que descubrió que Dalí podría hablar muy seriamente sobre ciencia. Por su lado, Dalí descubrió que Banchoff conocía a fondo la obra de uno de sus autores preferidos, el filósofo, matemático y teólogo medieval Ramon Llull. Juntos harán proyectos, la escultura de un caballo gigante basado en fórmulas matemáticas que nunca se hará realidad.

El óleo que les unió, el "Corpus hypercúbicus", presenta la figura de un Cristo crucificado que flota en el espacio delante de una cruz formada por ocho cubos. En realidad, esta peculiar cruz es un 
de pintar aquella escalera para Severo Ochoa, y que simbolizan los mensajeros genéticos de moléculas de nucleótidos sintetizados por primera vez en el laboratorio de Severo Ochoa.

Aunque no sea científico debo confesar que los acontecimientos científicos son los únicos que guían mi imaginación, al mismo tiempo que ilustran las intuiciones poéticas de los filósofos tradicionales hasta el punto de conseguir una belleza deslumbrante de determinadas estructuras matemáticas y de aquellos momentos sublimes de abstracción que vistos a través de un microscopio electrónico aparecen como virus de forma poliédrica, confirmando lo que Platón dijo: "Dios siempre hace geometría".

Dalí expresa en el texto su admiración por la belleza matemática de la naturaleza, que entronca con su interés por la obra del matemático rumano Matila Ghyka, que asesoró a Dalí en el planteamiento compositivo de "Leda atómica". De hecho, durante los años 50 Dalí se obsesiona por la presencia de estructuras matemáticas en la naturaleza. En 1954 lo encontramos en el museo del Louvre, inspeccionando con detalle el cuadro "La encajera", de Vermeer. Dalí admira profundamente al pintor holandés y quiere confirmar empíricamente una hipótesis (en cierto modo, también en su trabajo artístico aplicaba el método científico): según Dalí, el cuadro de Vermeer es una composición a base de cuernos de rinoceronte, formados por espirales logarítmicas que, para el pintor, era la estructura más perfecta de la naturaleza. Después de este examen ocular, Dalí da por confirmada su teoría y pinta una versión de "La encajera" descompuesta en cuernos de rinoceronte.

\section{El último gesto del artista}

“La persistencia de la memoria" (1931) es el cuadro daliniano que se ha convertido en icono de la teoría de la relatividad. Uno de los grandes admiradores de esta obra es el premio Nobel de química, Ilya Prigogine (fallecido meses después de la entrevista que concedió para el documental). Siempre había admirado la obra de Dalí, pero no lo conoció hasta 1985, durante el congreso científico "Proceso al azar", que Jorge Wagensberg, director del Museo de la Ciencia de Barcelona, organizó en Figueras, en el mismo Teatro-Museo. Dalí, ya enfermo, lo siguió por un circuito cerrado de televisión desde la Torre Galatea.

Además de Prigogine, la conferencia que aloja Dalí en su museo reúne a otros grandes nombres de la ciencia del momento, como el matemático francés René Thom, o Peter Landsberg. Entre el público, unas doscientas personas, muchos científicos pero también filósofos, escritores y artistas. Un circuito cerrado de televisión conecta la sala de actos con una habitación del museo. Delante de la pantalla, 
un solo espectador: Dalí. Es tan sólo una sombra del personaje que, años atrás, utilizaba los medios de comunicación a voluntad para proyectar al mundo una imagen de provocador excéntrico. Ha envejecido y está enfermo. Va en silla de ruedas y no soporta la sonda de plástico que lleva en la nariz. Hace tiempo que no pinta. Sin embargo, sigue ávidamente el congreso con la vista clavada en el monitor. Jorge Wagensberg lee en la inauguración un texto escrito para la ocasión por Dalí: “El fenómeno estético va estrechamente ligado a la historia de la ciencia, aunque tan sólo sea por el hecho de que en ambos se da la elección experimental".

Prigogine recuerda en el documental varios momentos del congreso. Uno, cuando en medio del evento se desató una discusión entre él mismo y René Thom ya que estaban en desacuerdo respecto a ciertas teorías. Dalí los llamó a su habitación y les pidió que "en el nombre de Schrödinger" hiciesen las paces. Ninguno de los dos supo interpretar esta afirmación, pero le hicieron caso. Otro de los momentos que recuerda es cuando todos los científicos ponentes visitaron a Dalí en su habitación. Él no pudo resistirse a preguntarle sobre el cuadro que tanto admiraba y su relación con la teoría de la relatividad. Aunque el pintor no le había dado una respuesta inmediata, el encuentro dio lugar a una interesante correspondencia entre el pintor y el científico. El que fue uno de sus secretarios, Antoni Pitxot, le leía estas cartas y los libros de Stephen Hawking, Matila Ghyka y Erwin Schrödinger. Eran las únicas lecturas que, en los últimos días de su vida, tranquilizaban su alma.

Recibido para publicación en octubre 2005.

Aprobado para publicación en febrero 2006. 